\title{
Analysis and Evaluation of Heavy Metal Pollution of Surface Soil in Baicheng City Based on Factor Analysis Method
}

\author{
Zhaoyang Qiao ${ }^{1, \text { a }}$ \\ ${ }^{1}$ School of Computer Science, Baicheng Normal College, Baicheng, 137000 China \\ aemail: qzy1969@126.com
}

\begin{abstract}
Keywords: Baicheng City; Heavy Metal Pollution in Soil; Fuzzy Comprehensive Evaluation Method; Factor Analysis Method
\end{abstract}

\begin{abstract}
In the thesis, the pollution condition of heavy metals in the soil is evaluated by fuzzy comprehensive evaluation method through testing and analyzing content of heavy metals (As Cd Cr $\mathrm{Cu} \mathrm{Hg} \mathrm{Ni} \mathrm{Pb} \mathrm{Zn)} \mathrm{in} 400$ sampling points within $400 \mathrm{~km}^{2}$ near Baicheng City; and types and sources of pollutions of heavy metals in the soil in Baicheng City are analyzed and studied by factor analysis method. scientific proof for soil improvement and phytoremediation in this area can be provided. It is indicated through the integrated evaluation of the test result that the living quarter, the main road area and the green belt are polluted slightly; the industrial area is polluted moderately. It can be seen through comprehensive analysis that there are three main sources of heavy metal pollutions in the surface soil in Baicheng City: industrial pollution source, traffic pollution source and house pollution source. Therefore, effective measures shall be taken by the local people in the protection of the soil encountered with the various pollution status of the functional areas.
\end{abstract}

\section{Introduction}

Along with fast promotion of industrialization and urbanization, lots of wastes generated from industry, traffic and business enter into soil; while penetrating into soil, pollutants with various heavy metals can pose danger to human health through several ways such as food chain and even induce diseases such as cancer[1]. Pollution of heavy metals to soil is irreverse, therefore, real-time analysis of content of heavy metals and taking preventative measures are very important for protecting the soil. In the research, the author analyzes pollution of heavy metals in soil and its sources and distribution based on Baicheng City and its surrounding areas, aiming at confirming conditions and distribution features of heavy metals in soil in the urban area and offering scientific basis to treating soil pollutions and ecological restoration.

\section{Sample Collection and Division of Functional Zone}

Divide Baicheng City into gridding areas with a distance of about $1 \mathrm{~km}$; sample and number the surface soil $(0 \sim 20 \mathrm{~cm}$ thick $)$ at each sampling points every $1 \mathrm{~km}^{2}$ and record the position of the sampling point by GPS. Conduct test and analysis by special instruments; then acquire the basis of thickness of various chemical elements contained in each sample. In addition, take samples in a natural area far away from crowds and industrial activities with a space of $2 \mathrm{~km}$ and regard them as the background value of elements in the surface soil in Baicheng City.

According to actual situations of Baicheng City, divide the urban area into the living quarter, the industrial area, the main road area and the green belt recorded as class 1 , class 2 , class 3 and class 4 ; human activities pose different influences upon the environment in different areas.

\section{Integrated Evaluation of Pollution Level of Heavy Metal in Soil}

\section{Evaluation standard.}

National Soil Environment Standard [2], Soil environmental background value in Baicheng City (see table 1), the evaluation standard drafted by Shu Dongni [3] (see table 3) and integrated evaluation grading standard for heavy metal pollution in soil offered by Zhang Chaolan [4] (see 
table 2) are applied in the research.

Table 1 Background value of 8 metal elements in Baicheng City

\begin{tabular}{|c|c|c|c|}
\hline Element & Average value & Standard deviation & Scope \\
\hline $\mathrm{As}(\mu \mathrm{g} / \mathrm{g})$ & 3.6 & 0.9 & $1.8 \sim 5.4$ \\
\hline $\mathrm{Cd}(\mathrm{ng} / \mathrm{g})$ & 130 & 30 & $70 \sim 190$ \\
\hline $\mathrm{Cr}(\mu \mathrm{g} / \mathrm{g})$ & 31 & 9 & $13 \sim 49$ \\
\hline $\mathrm{Cu}(\mu \mathrm{g} / \mathrm{g})$ & 13.2 & 3.6 & $6.0 \sim 20.4$ \\
\hline $\mathrm{Hg}(\mathrm{ng} / \mathrm{g})$ & 35 & 8 & $19 \sim 51$ \\
\hline $\mathrm{Ni}(\mu \mathrm{g} / \mathrm{g})$ & 12.3 & 3.8 & $4.7 \sim 19.9$ \\
\hline $\mathrm{Pb}(\mu \mathrm{g} / \mathrm{g})$ & 31 & 6 & $19 \sim 43$ \\
\hline $\mathrm{Zn}(\mu \mathrm{g} / \mathrm{g})$ & 69 & 14 & $41 \sim 97$ \\
\hline
\end{tabular}

Table 2 Grade of integrated evaluation standard for heavy metal pollution in soil

\begin{tabular}{|c|c|c|c|c|c|}
\hline Grade & I & II & III & IV & V \\
\hline$V_{j}$ & 10 & 20 & 30 & 40 & 50 \\
\hline Approach degree $\quad\left(V_{o} / V_{j}\right)$ & 1 & 0.5 & 0.33 & 0.25 & 0.20 \\
\hline Evaluation standard & 1.00 & $\geqslant 0.50$ & $\geqslant 0.33$ & $\geqslant 0.25$ & $\geqslant 0.20$ \\
\hline Pollution level & A & B & C & D & E \\
\hline
\end{tabular}

A, B, C, D, E represents extremely clean, clean, slight pollution, moderate pollution and heavy pollution. Similarly hereinafter.

Table 3 Grading standard for heavy metal pollution in soil

\begin{tabular}{|c|c|c|c|c|c|}
\hline Grade & 5 & 4 & 3 & 2 & 1 \\
\hline $\mathrm{As}(\mu \mathrm{g} / \mathrm{g})$ & $\leq 3.6$ & $\leq 5.4$ & $\leq 6.3$ & $\leq 7.2$ & $>7.2$ \\
\hline $\mathrm{Cd}(\mathrm{ng} / \mathrm{g})$ & $\leq 130$ & $\leq 190$ & $\leq 220$ & $\leq 250$ & $>250$ \\
\hline $\mathrm{Cr}(\mu \mathrm{g} / \mathrm{g})$ & $\leq 31$ & $\leq 49$ & $\leq 58$ & $\leq 67$ & $>67$ \\
\hline $\mathrm{Cu}(\mu \mathrm{g} / \mathrm{g})$ & $\leq 13.2$ & $\leq 20.4$ & $\leq 24$ & $\leq 27.6$ & $>27.6$ \\
\hline $\mathrm{Hg}(\mathrm{ng} / \mathrm{g})$ & $\leq 35$ & $\leq 51$ & $\leq 59$ & $\leq 67$ & $>67$ \\
\hline $\mathrm{Ni}(\mu \mathrm{g} / \mathrm{g})$ & $\leq 12.3$ & $\leq 19.9$ & $\leq 23.7$ & $\leq 27.5$ & $>27.5$ \\
\hline $\mathrm{Pb}(\mu \mathrm{g} / \mathrm{g})$ & $\leq 31$ & $\leq 43$ & $\leq 49$ & $\leq 55$ & $>55$ \\
\hline $\mathrm{Zn}(\mu \mathrm{g} / \mathrm{g})$ & $\leq 69$ & $\leq 97$ & $\leq 111$ & $\leq 125$ & $>125$ \\
\hline Pollution level & A & B & $\mathrm{C}$ & $\mathrm{D}$ & $\mathrm{E}$ \\
\hline
\end{tabular}

\section{Evaluation method.}

Fuzzy comprehensive evaluation method[4] is applied in the thesis to evaluate pollution condition of heavy metals in soil; first, the weight value $\alpha_{j}$ of each factor is calculated, and the sum of weight values is calculated according to $\sum_{j=1}^{m} \alpha_{j}$; then the weight coefficient of each factor can be calculated by the formula $\alpha_{j}=10 a_{j} / \sum_{j=1}^{m} \alpha_{j}$. The result is listed in table 4 .

Table 4 weight coefficient of heavy metals in soil in Baicheng City

\begin{tabular}{|c|c|c|c|c|c|c|c|c|}
\hline & $\mathrm{As}$ & $\mathrm{Cd}$ & $\mathrm{Cr}$ & $\mathrm{Cu}$ & $\mathrm{Hg}$ & $\mathrm{Ni}$ & $\mathrm{Pb}$ & $\mathrm{Zn}$ \\
\hline Weight in class 1 & 0.0882 & 0.1129 & 0.1127 & 0.1894 & 0.1364 & 0.0755 & 0.1129 & 0.1739 \\
\hline Weight in class 2 & 0.0464 & 0.0697 & 0.0397 & 0.2225 & 0.4227 & 0.0371 & 0.0691 & 0.0928 \\
\hline Weight in class 3 & 0.0517 & 0.0902 & 0.061 & 0.1535 & 0.4157 & 0.0466 & 0.0667 & 0.1146 \\
\hline Weight in class 4 & 0.1066 & 0.1323 & 0.0863 & 0.1402 & 0.2014 & 0.0762 & 0.12 & 0.137 \\
\hline
\end{tabular}


In order to calculate the approach degree of the evaluation standard, we should calculate the variable value of the index $u_{i j}=X_{i j} \alpha_{j}$ ( $X_{i j}$ is the score of index variable $j$ of sample $i$ and $\alpha_{j}$ is weight coefficient of sample $j$.) Then, calculate the sum of index variables $V_{i}=\sum_{j=1}^{m} u_{i j}$ and the sum of variables of samples contrasted with the standard $V_{0}=\sum_{j=1}^{m} x_{0 j} \alpha_{j}\left(X_{0 j}\right.$ is the standard grade in the formula, and is class I of clean, namely $X_{0 j}=1$ ); finally calculate the approach degree $N_{i}=\frac{V_{0}}{V_{j}}$.

\section{Integrated valuation.}

According to the approach degree, heavy metal pollution in soil in 4 areas in Baicheng City can be evaluated comprehensively by the integrated evaluation grading standard for heavy metal pollutions in soil in table 2; the result can be seen in table 5 .

Table 5 Integrated evaluation of heavy metal pollution in soil in Baicheng City

\begin{tabular}{|c|c|c|c|c|}
\hline Area & Living quarter & Industrial area & Main road area & Green belt \\
\hline Approach degree & 0.3358 & 0.2773 & 0.352 & 0.3907 \\
\hline Pollution level & C & D & C & C \\
\hline
\end{tabular}

\section{Analysis of Source of Heavy Metal Pollution in Soil}

\section{Analysis method.}

In order to analyze source of heavy metal pollution in soil, the method [5][6] in the article Main Sources of Heavy Metal Pollutions in Soil in Taiyuan City Based on Factor Analysis Method is applied as the following steps:

(1) Standardization of the original data; the formula is $X_{i j}-X_{j} / \delta_{j}$, in which $X_{i j}$ is the index value $j$ of sample $i$; while $X_{j}$ and $\delta_{j}$ are the average value and the standard deviation of index $j$. It aims at eliminating influences of dimensions of different variables; however, conversion of standardization will not change relevant coefficients of variables.

(2) Calculate relevant coefficient matrix of standardized data, and proper value and proper vector of the matrix of relevant coefficients.

(3) Use orthogonal transformation and maximum variance method to polarize factor loading; while the factor after revolving is still orthogonal.

(4) Confirm number of factors and calculate their scores for statistical analysis.

\section{Result analysis.}

In the thesis, indexes of $\mathrm{As}, \mathrm{Cd}, \mathrm{Cr}, \mathrm{Cu}, \mathrm{Hg}, \mathrm{Ni}, \mathrm{Pb}$ and $\mathrm{Zn}$ are used for factor analysis by SPSS18.0 statistics software after data standardization processing; then the matrix of relevant coefficients of content of 8 heavy metal elements is acquired. The living quarter is taken as an example to analyze and the result can be seen in table 6 .

Table 6 Matrix of relevant coefficients of 8 elements in the living quarter

\begin{tabular}{|c|c|c|c|c|c|c|c|c|}
\hline & $\mathrm{As}(\mu \mathrm{g} / \mathrm{g})$ & $\mathrm{Cd}(\mathrm{ng} / \mathrm{g})$ & $\mathrm{Cr}(\mu \mathrm{g} / \mathrm{g})$ & $\mathrm{Cu}(\mu \mathrm{g} / \mathrm{g})$ & $\mathrm{Hg}(\mathrm{ng} / \mathrm{g})$ & $\mathrm{Ni}(\mu \mathrm{g} / \mathrm{g})$ & $\mathrm{Pb}(\mu \mathrm{g} / \mathrm{g})$ & $\mathrm{Zn}(\mu \mathrm{g} / \mathrm{g})$ \\
\hline $\mathrm{As}(\mu \mathrm{g} / \mathrm{g})$ & 1 & 0.381 & 0.238 & 0.531 & 0.293 & 0.605 & 0.45 & -0.017 \\
\hline $\mathrm{Cd}(\mathrm{ng} / \mathrm{g})$ & 0.328 & 1 & 0.349 & 0.499 & 0.397 & 0.283 & 0.802 & 0.346 \\
\hline $\mathrm{Cr}(\mu \mathrm{g} / \mathrm{g})$ & 0.334 & 0.3 & 1 & 0.376 & 0.15 & 0.527 & 0.416 & 0.412 \\
\hline $\mathrm{Cu}(\mu \mathrm{g} / \mathrm{g})$ & 0.242 & 0.34 & 0.211 & 1 & 0.198 & 0.434 & 0.502 & 0.238 \\
\hline $\mathrm{Hg}(\mathrm{ng} / \mathrm{g})$ & 0.238 & 0.502 & 0.434 & 0.198 & 1 & 0.211 & 0.34 & 0.242 \\
\hline $\mathrm{Ni}(\mu \mathrm{g} / \mathrm{g})$ & 0.412 & 0.416 & 0.527 & 0.15 & 0.376 & 1 & 0.3 & 0.334 \\
\hline $\mathrm{Pb}(\mu \mathrm{g} / \mathrm{g})$ & 0.346 & 0.802 & 0.283 & 0.397 & 0.499 & 0.349 & 1 & 0.328 \\
\hline $\mathrm{Zn}(\mu \mathrm{g} / \mathrm{g})$ & -0.017 & 0.45 & 0.605 & 0.293 & 0.531 & 0.238 & 0.381 & 1 \\
\hline
\end{tabular}


It can be seen in the above stable that the correlation between $\mathrm{Pb}$ and $\mathrm{Cd}$ is the best; $\mathrm{Zn}, \mathrm{Cr}$, As and $\mathrm{Ni}$ is the second; while that between other elements is not good. It can be also seen from factors that elements with good correlation may be relevant in factors and sources.

The key of factor analysis is to calculate feature value and accumulated contribution rate of relevant factors by the matrix of relevant coefficients; those in the living quarter can be seen in table 7.

Table 7 Feature value and accumulated contribution rate of variables in the living quarter

\begin{tabular}{|c|c|c|c|c|c|c|}
\hline \multirow{2}{*}{ Factor } & \multicolumn{3}{|c|}{ Before revolving } & \multicolumn{3}{c|}{ After revolving } \\
\cline { 2 - 6 } & $\begin{array}{c}\text { Feature } \\
\text { value }\end{array}$ & $\begin{array}{c}\text { \% of } \\
\text { variance }\end{array}$ & $\begin{array}{c}\text { \% of } \\
\text { accumulated } \\
\text { contribution rate }\end{array}$ & $\begin{array}{c}\text { Feature } \\
\text { value }\end{array}$ & $\begin{array}{c}\% \text { of } \\
\text { variance }\end{array}$ & $\begin{array}{c}\text { of } \\
\text { accumulated } \\
\text { contribution rate }\end{array}$ \\
\hline 1 & 3.616 & 45.199 & 45.199 & 2.138 & 26.731 & 26.731 \\
\hline 3 & 1.133 & 14.165 & 59.365 & 2.09 & 26.119 & 52.85 \\
\hline
\end{tabular}

When the accumulated variance is $72.797 \%$, 3 main factors are acquired through analysis. It can be seen from the above table that the accumulated contribution rate before and after revolving does not change, namely, the total information does not miss. It can also be seen from the above table that the accumulated contribution rate of both main factor 1 and 2 is about $26 \%$, while that of main factor 3 is about 20\%, which means that main factor 1 and 2 contribute most to heavy metal pollution in the living quarter; and main factor 3 has important function.

Factor analysis aims at placing variables with similar factor loading under the same factor; the maximum rotation of the orthogonal variance makes each main factor related to the least variables so that the load of sufficient loads is very small and meaning of factors can be explained reasonably. The output result can be seen in table 8 .

Table8 The matrix of factor loading in the living quarter before and after revolving

\begin{tabular}{|l|c|c|c|c|c|c|}
\hline & \multicolumn{3}{|c|}{ Before revolving } & \multicolumn{3}{c|}{ After revolving } \\
\cline { 2 - 7 } & Factor 1 & Factor 2 & Factor 3 & Factor 1 & Factor 2 & Factor 3 \\
\hline $\mathrm{As}(\mu \mathrm{g} / \mathrm{g})$ & 0.669 & -0.646 & -0.010 & 0.300 & 0.868 & -0.148 \\
\hline $\mathrm{Cd}(\mathrm{ng} / \mathrm{g})$ & 0.784 & 0.171 & -0.417 & 0.849 & 0.224 & 0.216 \\
\hline $\mathrm{Cr}(\mu \mathrm{g} / \mathrm{g})$ & 0.643 & 0.234 & 0.493 & 0.105 & 0.405 & 0.733 \\
\hline $\mathrm{Cu}(\mu \mathrm{g} / \mathrm{g})$ & 0.729 & -0.246 & 0.024 & 0.400 & 0.635 & 0.169 \\
\hline $\mathrm{Hg}(\mathrm{ng} / \mathrm{g})$ & 0.492 & 0.130 & -0.437 & 0.666 & 0.066 & 0.048 \\
\hline $\mathrm{Ni}(\mu \mathrm{g} / \mathrm{g})$ & 0.686 & -0.253 & 0.523 & 0.006 & 0.785 & 0.439 \\
\hline $\mathrm{Pb}(\mu \mathrm{g} / \mathrm{g})$ & 0.803 & 0.112 & -0.348 & 0.798 & 0.302 & 0.226 \\
\hline $\mathrm{Zn}(\mu \mathrm{g} / \mathrm{g})$ & 0.501 & 0.691 & 0.267 & 0.277 & -0.083 & 0.846 \\
\hline
\end{tabular}

It can be seen in table 7 that the result of variables of loads of factors before and after revolving is basically identical. The larger the absolute value of the correlation coefficient between a variable and a factor is, the closer their relation is. It is explained in the orthogonal factor that factor 1 is the combination of $\mathrm{Pb}$ and $\mathrm{Cd}$; factor 2 is the combination of $\mathrm{Zn}$ and $\mathrm{Cr}$ and factor 3 is the combination of $\mathrm{As}$ and $\mathrm{Ni}$; each combination may come from a common source; and elements in three combinations are correlated at best.

In order to make analysis better, the contour line of factors distributed in the space can be drawn through the score of a single sample in the surface soil in Baiheng City on the 3 main factors after orthogonal revolving with maximum variance of 3 factors from factor analysis. 


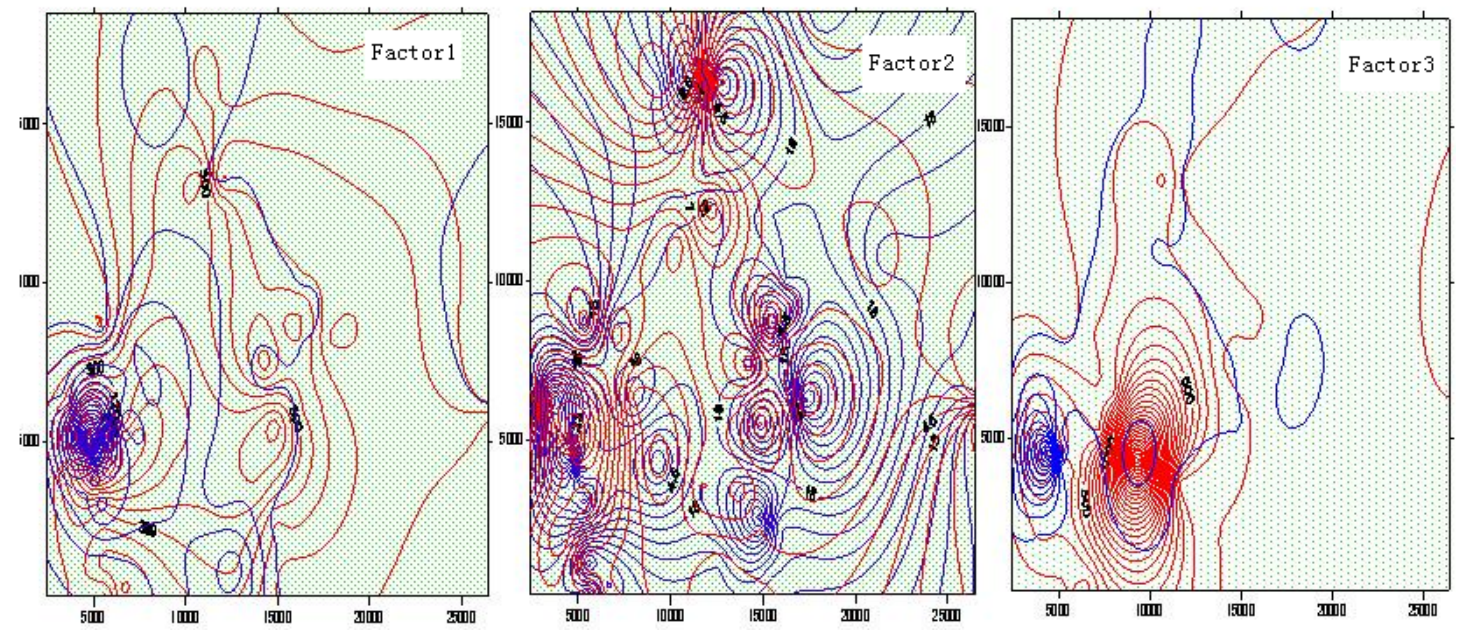

Fig-1 Distribution map of the contour line of main factors in the living quarter in the plane space

It can be seen through analyzing the distribution map of the contour line of 3 factors that sources of $\mathrm{Pb}$ and $\mathrm{Cd}$ is closely related. Main pollutants of $\mathrm{Pb}$ and $\mathrm{Cd}$ in the living quarter are from discharge of waste gas of automobiles, which spread with driving automobiles and wind power. The pollution area of $\mathrm{Zn}$ and $\mathrm{Cr}$ is large, indicating that pollution of these two metals mainly comes from additives of building materials of building in the urban areas and tyres of automobiles and waste batteries which are not processed well. As and Ni are concentrated-distributed, indicating that these two metals in the living quarter mainly come from use of pesticides and inferior chemical fertilizers in agricultural production.

Likewise, the following conclusions can be gained:

Industrial area: industrial energy sources mainly come from coal and petroleum, which are also the main sources of heavy metal pollutions such as $\mathrm{Hg}, \mathrm{Cr}$ and $\mathrm{Cd}$; meanwhile, discharge of three wastes in production of factories would cause lots of compounds of $\mathrm{Cu}$ and $\mathrm{Pb}$.

Living quarter: main pollutants in the living quarter $\mathrm{Cu}, \mathrm{Cr}$ and $\mathrm{Ni}$ mainly come from construction of roads, dust and refuse dumps on roads.

Green belt: main pollutants $\mathrm{Pb}, \mathrm{Cu}, \mathrm{Zn}, \mathrm{Ni}$ and $\mathrm{Cr}$ mainly come from house refuses from residents.

\section{Conclusion}

1)Results from the evaluation and analysis of the heavy metal pollution condition in Baicheng City soil by means of fuzzy comprehensive evaluation method show that mild pollution can be examined in the living areas and the green areas of the parks; while middle level pollution can be examined in the industrial zones. On the whole, the concentration distribution of heavy metal shows certain area difference which is mainly related to the functions of the areas and generally speaking, industrial areas and commercial areas are subject to heavy pollution.

2)Results from the research and analysis of the types and source of soil heavy metal pollution in Baicheng City via factor analysis show that the major pollution factors $\mathrm{Hg}, \mathrm{Cr}, \mathrm{Cd}, \mathrm{Cu}$ and $\mathrm{Pb}$ of industrial areas are mainly from coal emissions and "three wastes" discharge from factories; the major pollution factors $\mathrm{Pb}, \mathrm{Cu}, \mathrm{Zn}, \mathrm{Ni}$ and $\mathrm{Cr}$ of the green areas of the parks mainly come from household garbage deserted by residents; the major pollution factors $\mathrm{Cu}, \mathrm{Cr}$ and $\mathrm{Ni}$ of the main roads are mainly from road construction, dust emission and road landfill; the major pollution factors $\mathrm{Pb}, \mathrm{Cd}, \mathrm{Zn}, \mathrm{Cr}$, As and Ni of living areas mainly come from vehicle exhaust emission, usage of addition agent for building materials and tires, improper disposal of wasted batteries and usage of pesticides and chemical fertilizers.

\section{References}

[1] Bai Houyi etc., evaluation about heavy metal pollution in soil in Nanning Tanluo ecological planning area [J], Journal of Guangxi University, 29(2): 165-169, 2004. 
[2] State Environmental Protection Bureau, soil environment standard [M]. Beijing: China Standards Press, 1995.

[3] Shu Dongni, discussion and evaluation about pollution level of heavy metals in soil by fuzzy mathematics comprehensive evaluation method [J], Agricultural Environment Protection, 8(5):30-32, 1989.

[4] Zhang Chaolan and Bai Houyi, evaluation about pollution level of heavy metals in soil by fuzzy comprehensive evaluation method [J], Guangxi Agricultural and Biological Sciences, 22(1):54-57, 2003.

[5] Wang Xiongjun etc., Main Sources of Heavy Metal Pollutions in Soil in Taiyuan City Based on Factor Analysis Method [J], Environment, 17(2):671-676, 2008.

[6] Li Lianke, judgment of sources of air pollutions in offshore areas by factor analysis method [J], Marine Environmental Science, 17(1): 30-34, 1998. 